\section{Physical functional profile of hospitalized Brazilian older adults in preoperative vascular surgery}

Juliana Verdini de Carvalho Pinheiro, Mariana Fonseca Vaz, ${ }^{2}$

Ana Paula Novello, ${ }^{2}$ Leonardo Fonseca, ${ }^{3}$

Tiago Batista da Costa Xavier, ${ }^{4}$

Luciana Moisés Camilo, ${ }^{1,4}$

Marco Orsini, 5,6

Marco Antonio Alves Azizi, 5

Cristiane Sousa Nascimento Baez Garcia, ${ }^{4}$

Mauricio de Sant' Anna Jr ${ }^{1,4}$

${ }^{1}$ Professional Master's Degree Program

in Biomedical Research Training, Carlos

Chagas Filho Institute of Biophysics,

Federal University of Rio de Janeiro,

Rio de Janeiro, RJ, Brazil; ${ }^{2}$ Pedro

Ernesto University Hospital, Rio de

Janeiro, RJ, Brazil; ${ }^{3}$ State Servant

Federal Hospital, Rio de Janeiro, RJ,

Brazil; ${ }^{4}$ Federal Institute of Education,

Science and Technology of Rio de

Janeiro, RJ, Brazil; 'Iguaçu University,

School of Medicine, Rio de Janeiro, RJ,

Brazil; ${ }^{6}$ Vassouras University, Rio de

Janeiro, RJ, Brazil

\begin{abstract}
The objective of the present study was to describe the physical and functioning profile of Brazilian older adults admitted to avascular surgery wards (VSW). This is an observational and cross-sectional study using patients admitted to VSW. The study included subjects considered able to (group $1, \mathrm{G} 1)$ or restricted to physical and functional assessment (group 2, G2). Barthel index (BI) was evaluated in $\mathrm{G} 1$ and $\mathrm{G} 2$ groups, while hand grip strength (HGS), Timed up and Go (TUG), maximal inspiratory and expiratory pressures (MIP and MEP respectively) were assessed only in G1. The data of a total of 104 older adults $(\mathrm{G} 1=56$ and $\mathrm{G} 2=48)$ were analyzed. Most patients had good bed mobility $(83.9 \%$ in G1 and $75 \%$ in G2). There were significant difference between the predicted values and the recorded values obtained for MIP, MEP and HGS $(\mathrm{P}<0.0001)$. Pearson correlation showed a significant association between HGS and TUG $(\mathrm{P}=0.005 / \mathrm{r}=-0.384)$ and MEP and TUG $(\mathrm{P}=0.009 / \mathrm{r}=-0.353)$. In conclusion, hospitalized older adults able to perform functional tests showed reduced HGS, MIP and MEP, as well as moderate risk of falls. There was also an association
\end{abstract}

of peripheral muscle strength and expiratory muscle strength with functional mobility evaluated by TUG.

\section{Introduction}

In developing countries, the World Health Organization considers older persons, adults aged 65 years and above. ${ }^{1}$ This reference, however, is valid for inhabitants of developed countries. In developing countries, such as Brazil, the third age begins at 60 years of age.

The Brazilian population is in a process of demographic restructuring, showing a decrease in fertility rates, a reduction in mortality and a consequent increase in life expectancy. With the demographic transition, the morbidity and the mortality profiles were modified, where acute conditions were replaced by chronic illness with health-care system impacts. With improvement of living conditions, life expectancy increased by 25.4 years between 1960 and 2010 , from 48 to 73.4 years. It is projected to increase to 81.29 years by $2050 .^{2}$

This segment of the population, due to the aging process itself, has a higher prevalence of chronic non-communicable diseases. ${ }^{1}$ The socioeconomic impact of chronic non-communicable diseases is increasing and it is considered a global public health problem. Among the non-communicable chronic diseases, we have vascular diseases (VD). Aging tends to increase the incidence of VD and consequently its costs with hospitalizations. $^{3}$

One of the main risk factors for older adults is hospitalization due to poor nutrition, excessive rest, sleep deprivation and polypharmacy. ${ }^{4}$ In addition, the older adults have a longer hospital stay, a slower and more complicated recovery. ${ }^{3,4}$

A phenomenon commonly expected for hospitalized older adults, due to the clinical, physical and psychological vulnerability inherent in the aging process, is functioning decline, which can lead to loss of autonomy and independence. ${ }^{5}$

An important predictor of adverse events during hospital admission is the combination of geriatric syndromes and diseases, which are associated with functional and cognitive decline, institutionalization, and post-discharge mortality. ${ }^{6}$ According to De Brauwer et al. ${ }^{7}$, acutely admitted inpatients are becoming older and functioning profile should be investigated early as its decline has implications for important public health implications.

According to the literature, the functioning decline may reach about $25 \%$ to $35 \%$ of hospitalized older adults. ${ }^{7}$ Therefore, a mul-
Correspondence: Mauricio de Sant Anna Jr, Instituto Federal de Educação, Ciência e Tecnologia do Rio de Janeiro, Campus Realengo. Rua Professor Carlos Wenceslau, 343 - Realengo, Rio de Janeiro -

cep: 21715-000, Brazil.

Tel.: +55.21.346.34497.

E-mail: mauricio.junior@ifrj.edu.br

Key words: Geriatric physical therapy; strength; functional mobility.

Acknowledgements: The Physical Therapy Service of the Federal Hospital of State Servants - RJ; the Physical Therapy Service of the Pedro Ernesto University Hospital RJ; and Vascular Surgery Services. Financial support: The National Council for Scientific and Technological Development (CNPq), and Federal Institute of Education, Science and Technology of Rio de Janeiro (IFRJ).

Contributions: JVdCP, MFV, LMC, CSNBG, MdS'AJ: i) conception and design, or analysis and interpretation of data; and to ii) drafting the article or revising it critically for important intellectual content; and on iii) final approval of the version to be published. APN, LF, TBdCX, MO, MAAA: ii) drafting the article or revising it critically for important intellectual content; and on iii) final approval of the version to be published.

Conflict of interests: the authors declare no potential conflict of interests.

Received for publication: 27 December 2019. Revision received: 8 May 2020.

Accepted for publication: 21 May 2020.

This work is licensed under a Creative Commons Attribution-NonCommercial 4.0 International License (CC BY-NC 4.0).

${ }^{\circ}$ Copyright: the Author(s), 2020

Licensee PAGEPress, Italy

Geriatric Care 2020; 6:8784

doi:10.4081/gc.2020.8784

tidisciplinary care team is necessary to identify functioning decline at admission and during the hospitalization period, guiding the measures to be taken, in order to reduce the risks of complications and improve the quality of life of these patients.

Aging is a multifactorial process, so it is necessary to know the physical and functioning profile of the older adult population. Such knowledge will provide the necessary subsidies for a comprehensive promotion of health and prevention of functioning decline during hospitalization of this population. Thus, the aim of this study was to describe the physical and functioning profile of a population of Brazilian older adults' patients admitted to vascular surgery wards (VSW). 


\section{Materials and Methods}

This is an observational and cross-sectional study conducted from May 2016 to May 2018 using a convenience sample composed of older adults admitted to VSW of the Federal Hospital of State Servants - RJ and Pedro Ernesto University Hospital - RJ.

Adults aged 60 years and above admitted to VSW were included in the study. Exclusion criteria were: hemodynamic instability; delirium status; cognitive deficit that impaired comprehension of tests; inability to communicate verbally and / or absence of a companion who could answer for the patient.

The study included subjects considered able to (group 1, G1) or restricted to physical and functional tests (group 2, G2).

All patients (G1 and G2 groups) were evaluated using the Barthel index (BI), , while hand grip strength (HGS), Timed up and Go (TUG) and maximal inspiratory and expiratory pressures (MIP and MEP, respectively) were assessed only in G1 group. Those patients who were unable to submit to physical tests due to contraindications or physical and/ or cognitive limitations were considered restricted to physical and functional tests (G2). Patients able to perform physical tests and who did not have conditions such as abdominal aortic aneurysm; dyspnea in functional class IV by the New York Heart Association; presence of drains; continuous venous infusion; pain assessed by visual analogue scale with score $\geq 8$; musculoskeletal disease that would prevent evaluation; zero diet and deep venous thrombosis were enrolled to group 1 (G1), as shown in Figure 1.

\section{Functioning assessment Barthel Index}

The Barthel Index (BI) was used to measure independence and need for assistance in personal care, mobility/ transference, locomotion and bladder and sphincter control. Each item was scored according to the patient's ability to perform the task independently, with help or with dependence. BI scores range from 0 to 100 , in steps of 5, with higher scores indicating greater independence. ${ }^{8}$ In this study, we used the classification suggested by Shah et al., ${ }^{9}$ which categorizes a score of 0-20 points as total dependence, 21-60 points severe dependence, 61-90 points moderate dependence, 91-99 points light dependence and independence for those who reach 100 points.

\section{Hand grip strength}

Hand grip strength (HGS) was evaluated using analog dynamometry (Jamar ${ }^{\circledR}$ PC5030J1, Fit Systems Inc, Calgary, Canada - 2014). To perform the test, participants sat upright, the arm was placed in accordance with the American Society for Hand Therapists guidelines. ${ }^{10}$ Three measurements were performed in the dominant hand with an interval of one minute between each measurement. Three measures were performed in the dominant (D) hand with a one-minute interval between each measurement. The average of the three assessments was recorded. In order to determine the predicted value of HGS, we used reference equation for predicting of handgrip strength in Brazilian elderly subjects proposed by Novaes et al. ${ }^{11}$ [DHGS kgf=39,996 - $(0,382 \times$ age years $)+$ $(0,174 \mathrm{x}$ weight $\mathrm{kg})+(13,628 \times \mathrm{x}$ sex men $=1$, women=0).

\section{Timed up and go test}

Timed Up and Go Test (TUG) was performed with the individuals using their regular footwear and their customary walking aid if necessary. No physical assistance was given. The subjects had to stand from a standardized chair, walk a straight threemeter path, turn around, walk towards the chair and sit down again. Two tests were performed: a first test for training, followed by another one for the assessment (measured in seconds). ${ }^{12}$ A time of 12.47 seconds was used as the predictive value of falling. ${ }^{13}$

\section{Maximum static inspiratory and expiratory respiratory pressures}

Maximum static inspiratory (MIP) and expiratory (MEP) pressures were obtained by an analog manovacuometer (M120 healthcare ${ }^{\circledR}$, São Paulo, Brazil - 2001).

For MIP evaluation, individuals performed forced inspirations starting from lung volume closest to residual volume (RV); and for MEP, expiratory efforts were performed starting from the total lung capacity (TLC). The maximal respirator efforts were sustained for a period of three seconds. The mouthpiece had a $2 \mathrm{~mm}$ hole, with the purpose of dissipating the pressures generated by the musculature of the face and oropharynx. ${ }^{14}$ To perform the test, the individual remained seated, with the trunk erect and feet parallel. At least three measurements of each maximum respiratory effort were performed with a one $\square$ minute rest between them. If the last one was the largest, more measurements were obtained until a lower value was reached. The second $\square$ largest measure could not differ by more than $10 \%$ from the largest. ${ }^{15}$ We used reference equations for predicting of MIP and MEP proposed by Neder et al. $(1999)^{15}$ for men: $\mathrm{MIP}=155.3-$ $0.80 \times$ age $(\mathrm{EPE}=17.3)$ and $\mathrm{MEP}=165.3-$ $0.81 \times$ age $(\mathrm{EPE}=15.6)$; and for women: $\mathrm{MIP}=110.4-0.49 \times$ age $(\mathrm{EPE}=9.1)$ and $\mathrm{MEP}=115.6-0.61 \mathrm{x}$ age $(\mathrm{EPE}=11.2)$.

\section{Ethical considerations}

The protocol of this study was approved by the Research Ethics Committee of both the Federal Hospital of State Servants - RJ

Figure 1. Distribution of the study participants regarding the groups. MIP, maximal inspiratory pressure; MEP, maximal expiratory pressure. 
(C.A.A.E: 54948116.7.0000.5252) and Pedro Ernesto University Hospital - RJ (C.A.A.E: 52632415.0.0000.5259). All participants were volunteers and signed the Free and Informed Consent Form according to Resolution 466/12 of the National Health Council of Brazil.

\section{Statistical analysis}

The appropriate sample size was calculated using GPower 3.1® software (University Düsseldorf, Germany - 2014) from previously published study, ${ }^{6}$ adjusting the power of the statistical test to 0.8 and the alpha error to 0.05 and beta error to $95 \%$, finding " $\mathrm{n}$ " of 88 subjects. The data obtained were charted and organized in spreadsheet calculations and presented by mean \pm standard deviation (normal distribution). GraphPad Prism 5® (San Diego, CA, USA) was used to analyze the results and to make the graphs, using the $5 \%$ significance level. To characterize the distribution and to compare the expected and obtained values, in addition to the comparison between the groups, the t test or its corresponding nonparametric test was used. Pearson's correlation was used to determine the association between the variables.

\section{Results}

A total of 104 participants were evaluated. The division between the groups can be observed in Figure 1. The demographic and clinical characteristics of the recruited participants are described in Table 1. Regarding the causes of hospitalization, the highest prevalence in G1 was arterial VD $(88.7 \%)$ and venous VD (11.3\%). There were no subjects with aortic aneurysm. In G2, arterial VD represented $41.8 \%$, aortic aneurysm $39.7 \%$ and venous VD $18.5 \%$ of hospitalizations with surgical indications.

Regarding the previous pathological history in the G1 group, $71.4 \%$ had hypertension and $31.1 \%$ diabetes. Still in the G1 group, $12.5 \%$ already suffered from some previous amputation, with no reported complications. The previous pathological history in the G2 group is distributed as follows: $70.83 \%$ had hypertension, $62.5 \%$ diabetes and $20.3 \%$ have suffered from some previous amputation, of whom $60 \%$ presented infection as a complication of amputation. The prevalence of smokers and former smokers in the G1 group was $42.6 \%$ and $21.4 \%$, respectively; and in G2 group $35.4 \%$ were smokers and $10.4 \%$ were former smokers.

In the G1 group, it was found that $39.2 \%$ of the older adults had experienced a falling episode last year. The mean time of execution for TUG test was 12.08 seconds, characterizing absence of fall risk. In the G2 group, $35.4 \%$ had experienced a falling episode last year, but due to the methodological design used at the present study, they didn't perform TUG test.

In the G1 group, at the time of the assessment, $30.3 \%$ of older adults had cough, compared to $39.5 \%$ in the G2 group $(\mathrm{P}=0.832)$. When the reported dyspnea was assessed, it was found $7.1 \%$ in the G1 group compared to $14.5 \%$ in the G2 group $(\mathrm{P}=0.080)$.

Regarding bed mobility, $83.9 \%$ of subjects in the G1 group had good bed mobility and did not need assistance to wander or sit in the chair; compared to $75 \%$ in the $\mathrm{G} 2$ group. Regarding limitation of mobility and transfers, we observed $16.1 \%$ in the G1 group and $25 \%$ in the $\mathrm{G} 2$ group.

The mean scores for BI were 94.8 and 84 in the G1 and G2 groups, respectively. Regarding the dimensions of BI, the category of greater dependence was on bladder and sphincter control in both groups; reports of urinary incontinence were found in $28.5 \%$ of subjects in the G1 group and $35.4 \%$ in the G2 group. In Figure 2, we can observe the characterization of independence and need for assistance in personal care, mobility/ transference, locomotion and bowel control of both groups.

A significant difference was observed

Table 1. General characteristics of the study population by group.

\begin{tabular}{lccc} 
Variables & G1 $(\mathrm{n}=56)$ & G2 $(\mathrm{n}=48)$ & $\mathrm{P}$ \\
Age (years) & $69.3 \pm 6.4$ & $72.0 \pm 7.3$ & 0.1294 \\
Gender male* $(\%)$ & 62.5 & 50 & 0.2386 \\
\hline Height $(\mathrm{m})$ & $1.6 \pm 0.9$ & $1.6 \pm 0.10$ & 0.3026 \\
Body weight $(\mathrm{kg})$ & $67.8 \pm 14.5$ & $71.3 \pm 15.5$ & 0.7379 \\
\hline BMI $\left(\mathrm{kg} / \mathrm{m}^{2}\right)$ & $25.7 \pm 4.7$ & $27.2 \pm 5.3$ & 0.2124 \\
SBP $(\mathrm{mmHg})$ & $130.2 \pm 20.3$ & $126.8 \pm 18.5$ & 0.7290 \\
\hline DBP $(\mathrm{mmHg})$ & $72.9 \pm 14.5$ & $75.6 \pm 14.5$ & 0.2335 \\
HR $(\mathrm{bpm})$ & $72.0 \pm 13.0$ & $77.0 \pm 18.0$ & 0.3142 \\
\hline POS $(\%)$ & $96.6 \pm 2.6$ & $94.7 \pm 3.8$ & 0.4138 \\
RF (irpm) & $18.4 \pm 3.4$ & $19.7 \pm 7.8$ & 0.3919 \\
\hline
\end{tabular}

Values in mean \pm standard deviation. *Variable analyzed by chi-square test. BMI, body mass index; SBP, systolic blood pressure; DBP, diastolic blood pressure; HR, heart rate; RF, respiratory frequency; POS2, peripheral oxygen saturation.

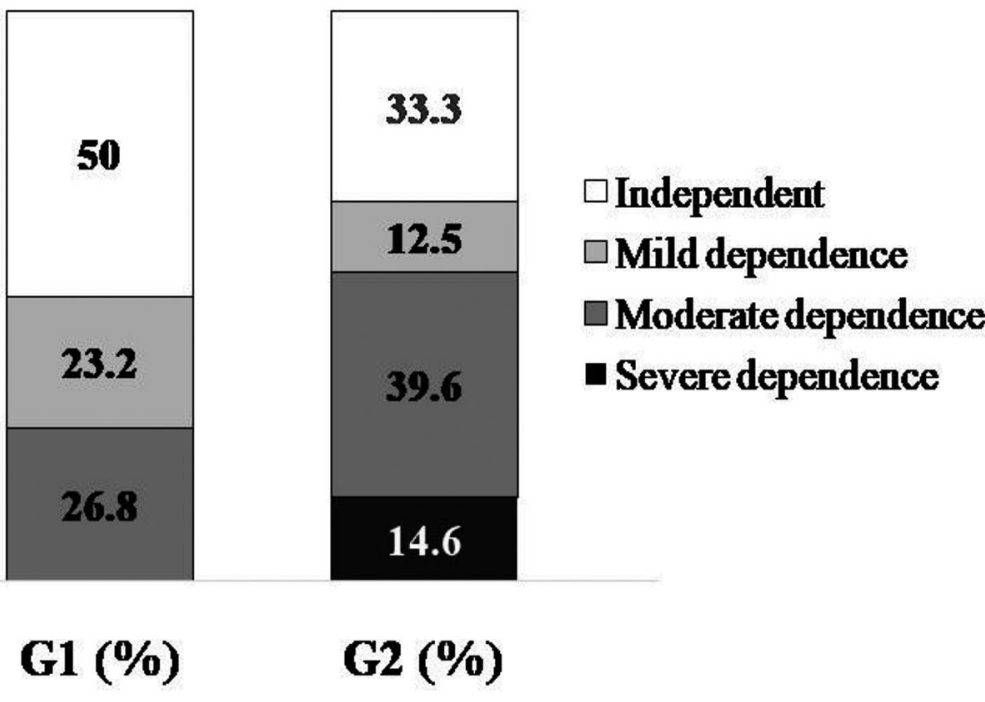

Figure 2. Characterization of the study participants regarding independence and need for assistance in personal care, mobility/ transference, locomotion and bladder and sphincter control assessed by the Barthel index, where G1 (group 1) are hospitalized older adults able to while G2 (group 2) are restricted to physical and functional assessment. 
between the predicted values and the recorded values of MIP $(\mathrm{P}<0.0001)$ and MEP $(\mathrm{P}<0.0001)$. The same behavior was observed for HGS $(\mathrm{P}<0.0001)$, as can be seen in Figure 3.

Pearson correlation showed a significant association between HGS and TUG $(\mathrm{P}=0.005 / \mathrm{r}=-0.384)$ and MEP and TUG $(\mathrm{P}=0.009 / \mathrm{r}=-0.353)$ as shown in Figure 4. No correlation was between MIP and TUG $(\mathrm{P}=0.352 / \mathrm{r}=-0.129)$.

\section{Discussion}

VDs have a high incidence and prevalence, especially in the elderly population, being the cause of mortality, morbidity and use of health resources in several countries in the world, which can cause irreversible damage to health and disabilities. ${ }^{16}$

We observed in the results of the study that G2 components (which did not perform functional tests) obtained higher mean age, more comorbidities, falling experience in the last year, as well as dependence on basic activities of daily living and bed mobility/ transfers.

In the study by Noto et al. ${ }^{17}$ performed with older adults without VD, the presence of diabetes and hypertension were associated with an increased risk of vascular events. In the study by Cabrera et al., ${ }^{16}$ the prospective analysis showed that diabetes and hypertension increased the risk of VD regardless of the other components of the metabolic syndrome, such as abdominal obesity and hypertriglyceridemia. In our study, a high prevalence of individuals with hypertension and diabetes was found in both groups, mainly in the G2 group.

Smoking is also considered a risk factor for VD. According to Rigotti and Nancy, ${ }^{18}$ a person with VD who smokes increases the risk of death by up to three times. The authors also suggested that quitting smoking before age 40 reduces the risk of death attributed to smoking by $90 \%$, but quitting at any age reduces mortality rates. In our study we found a high percentage of smokers and former smokers in both groups.

We could observe that subjects in the G2 group components exhibited higher mean age and also higher dependence than those in the G1 group. The study by Leinonen et al ${ }^{19}$ showed that health, physical performance and functioning decline with advancing age. Based on our data, we believe that advancing age increases the disabilities and the dependence as assessed by the BI.

The functioning assessment of the subjects in our study reveals that $50 \%$ of older adults in the G1 group have independence on ADL. The higher dependence on ADL in both groups was due to urinary incontinence. This fact is worrying since it can lead to social isolation and changes in selfesteem and self-image, influencing the instrumental activities of daily living.

Talarska et al..$^{20}$ reported that falls affect approximately $30 \%$ of elderly population per year. There is a great interest in reducing the number of falls in the older adults, in order to reduce social and health care expenses. Our results indicate that in both groups the older adults had experienced a falling episode last
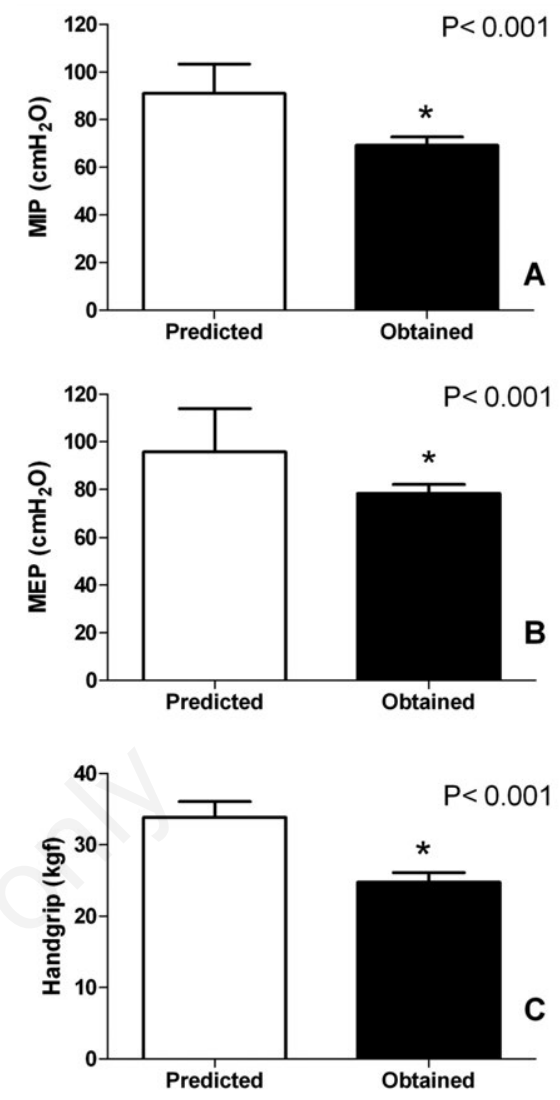

Figure 3. Comparison between predicted and obtained maximal inspiratory pressure (MIP) "A", maximal expiratory pressure (MEP) " $B$ " and hand grip strength " $C$ " in the G1 (group 1), characterized by hospitalized older adults able to while G2 (group 2) are restricted to physical and functional assessment. ${ }^{*}$ Statistical significance $\mathbf{P}<0.05$.
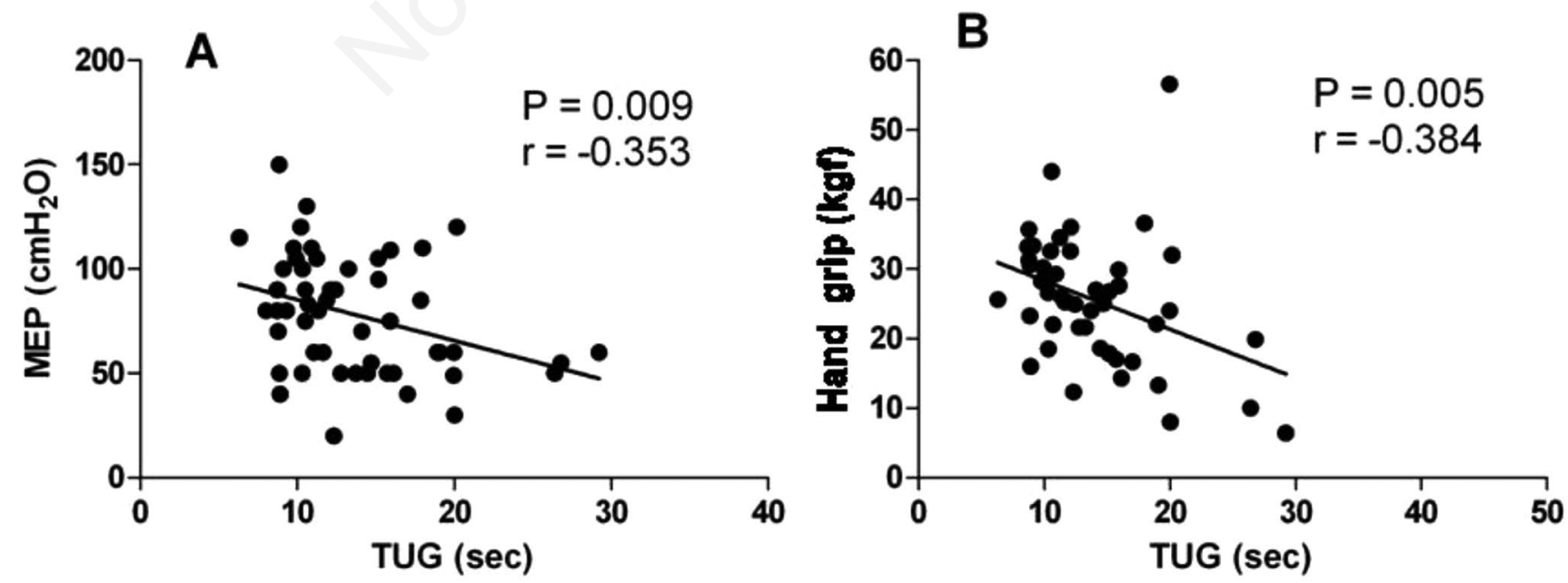

Figure 4. Pearson correlation between maximum static expiratory (MEP) pressure and timed up and go test (TUG) " $\mathrm{A}$ ", and hand grip strength and TUG "B" in the G1 (group 1), characterized by hospitalized older adults able to while G2 (group 2) are restricted to physical and functional assessment. 
year. Although falls are frequent events, and with multifactorial spectrum, it is difficult to establish a risk factor. ${ }^{21}$

The TUG is a widely used test in the older adults for assessment of gait speed and physical performance. In addition, the result obtained is associated with the risk of falls in this population. ${ }^{22,23}$ The gait speed is a variable described as being a good indicator for the risk of falls. According to the study by Talarska et al., ${ }^{20}$ older adults who obtain longer time to perform TUG, not only walk more slowly, but mainly in an insecure way.

Martinez et al..$^{23}$ reported that the results obtained in the TUG are associated with sarcopenia in hospitalized older adults. It is therefore suggested that the test may be useful in assessing this group of subjects. Visser and Schaap ${ }^{24}$ indicate the TUG to assess the risk of falls, as a predictor of functional decline and mortality in older adults without a reduction in muscle strength.

The cut-off point suggested by Martinez et al..$^{23}$ for sarcopenia was $\geq 10.85$ seconds to perform the test. Our subjects in the G1 group had an average time of 12.08 seconds. These findings allow us to infer that possibly they have sarcopenia, since they also present a reduction in HGS. According to the authors, one of the reasons why the TUG test predicts sarcopenia with good accuracy may be the significant peripheral muscle involvement that is required to rapidly transfer from a sitting position to the orthostatic position, which is one of the test activities.

HGS is a simple, reliable and feasible measure in many populations, and it can be used in patients with low collaboration and different degrees of comorbidity. ${ }^{25}$ It is characterized by total muscular strength of the upper extremities and also correlates with the strength of the lower extremities. ${ }^{26}$ It can be used as a predictor of the general state of strength and is related to mortality and disability. ${ }^{27}$ Thus, the better the result obtained by the older adults in dynamometry, the greater overall strength the individual will have. Our findings demonstrated a reduction in HGS in hospitalized older adults.

The association between HGS and TUG that we found corroborates with the study of Beseler et al. ${ }^{25}$ This study was conducted with 50 individuals observing that HGS is associated with the ability to walk in the frail hospitalized older adults and it serves as a prognostic factor of the ability to walk.

We also observed that subjects in the G1group present lower values than those predicted for respiratory muscle strength. Some studies have shown that aging is associated with reduced strength of respiratory muscles. Simões et al. ${ }^{28}$ evaluated 100 healthy individuals between 40 and 89 years of age and found that there was a significant and progressive decrease in respiratory muscle strength with aging. Related studies show that this reduction is directly related to the age; every decade there is a reduction of about $15 \%$ of respiratory muscle strength. ${ }^{29}$

No previous study was described a correlating between the maximum static respiratory pressures and TUG performance. However, in the Buchman et al. study ${ }^{30}$ study which evaluated 890 outpatients, respiratory muscle strength was associated with the rate of change in mobility.

\section{Limitations of the study}

Although it can be considered that we used the necessary methodological rigor to collect data, there were some limitations in the present study, such as: i) the lack of follow-up of the included patients, which did not allow establishing the association between the length of hospital stay and functioning/ disabilities; ii) drugs used; iii) complementary examinations carried out by the participants.

\section{Conclusions}

We conclude that the Brazilian older adults admitted to vascular surgery wards able to perform functional tests showed reduced peripheral and respiratory muscle strength, as well as moderate risk of falls. An association of peripheral muscle strength and expiratory muscle strength with functional mobility was also observed. Regarding activity limitations, both groups exhibited limited bed mobility and transfers, and greater dependence on bladder and sphincter control. It is suggested the investigation of other factors such as sociocultural, demographic and cognitive factors that also affect the functioning of elderly population.

\section{References}

1. World Health Organization (WHO). Active Ageing - A Police Framework. A Contribution of the World Health Organization to the second United Nations World Assembly on Aging. 2002.

2. Santos CD, Caldas JMP, Serafim JA, Barros N, Pereira AC. Hospital Admissions of Cancer Patients in Brazil: Analysis of Palliative Care Needs. J Palliat Care Med. 2016;6(3):16. doi: 10.4172/2165-7386.1000263. 3. Siqueira ASE, Siqueira-Filho AG, Land
MGP. Analysis of the Economic Impact of Cardiovascular Diseases in the Last Five Years in Brazil. 2017 Jul;109(1): 39-46. doi: 10.5935/abc.20170068.

4. Pereira EEB, Souza ABF, Carneiro SR, Sarges ESNF. Funcionalidade global de idosos hospitalizados. Rev. Bras. Geriatr. Gerontol. 2014 Mar; 17(1): 165-176. doi: 10.1590/S1809-98232014000100016.

5. Åhlund K, Ekerstad N, Öberg B, Bäck M. Physical Performance Impairments and Limitations Among Hospitalized Frail Older Adults. J Geriatr Phys Ther. 2018 Oct/Dec;41(4):230-235. doi: 10.1519/JPT.0000000000000127.

6. Buurman BM, Hoogerduijn JG, de Haan RJ, Abu-Hanna A, Lagaay AM, Verhaar HJ, Schuurmans MJ, Levi M, de Rooij SE. Geriatric conditions in acutely hospitalized older patients: prevalence and one-year survival and functional decline. PLoS One. 2011;6(11):e26951. doi: 10.1371/journal.pone.0026951.

7. De Brauwer I, Cornette P, Boland B, Verschuren F, D'Hoore W. Can we predict functional decline in hospitalized older people admitted through the emergency department? Reanalysis of a predictive tool ten years after its conception. BMC Geriatr. 2017 May;17(1):105. doi: 10.1186/s12877-017-0498-0.

8. Mahoney FI, Barthel D. Functional evaluation: The Barthel Index." Maryland State Medical Journal 1965;14:56-61.

9. Shah S, Vanclay F, Cooper B. Improving the sensitivity of the Barthel Index for stroke rehabilitation. J Clin Epidemiol. 1989;42(8):703-9. doi: 10.1016/0895-4356(89)90065-6.

10. Fess EE. Grip strength. In: Casanova JS, editor. Clinical assessment recommendations. 2nd ed. Chicago: American Society of Hand Therapists; 1992, p. 41-45.

11. Novaes RD, Miranda AS, Silva JO, Tavares BVF, Dourado VZ. Reference equations for predicting of handgrip strength in Brazilian middle-aged and elderly subjects. Fisio ter Pesq. 2009;16(3):217-22. doi: 10.1590/S180929502009000300005

12. Podsiadlo D, Richardson S. The timed "Up \& Go": A test of basic functional mobility for frail elderly persons. J Am Geriatr Soc. 1991 Feb;39(2):142-8. doi: 10.1111/j.1532-5415.1991.tb01616.x

13. Alexandre TS, Meira DM, Rico NC, Mizuta SK. Accuracy of Timed Up and Go Test for screening risk of falls among community-dwelling elderly. Rev Bras Fisioter. 2012 Sep-Oct;16(5):381-8. doi: 10.1590/s1413-35552012005000041

14. Mayos M, Giner J, Casan P, Sanchis J. Measurement of maximal static respira- 
tory pressures at the mouth with different air leaks. Chest. 1991 Aug;100(2):364-6. doi: 10.1378/chest.100.2.364

15. Neder JA, Andreoni S, Lerario MC, Nery LE. Reference values for lung function tests: II. Maximal respiratory pressures and voluntary ventilation. Braz J Med Biol Res. 1999 Jun;32(6):719-27. doi: 10.1590/s0100879x1999000600007

16. Agnelli G, Belch JJF, Baumgartner I, Giovas P, Hoffmann U. Morbidity and mortality associated with atherosclerotic peripheral artery disease: A systematic review. Atherosclerosis. 2020 Jan;293:94-100. doi: 10.1016/j.atherosclerosis.2019.09.012.

17. Noto D, Cefalù AB, Barbagallo CM, Sapienza M, Cavera G, Nardi I, Pagano M, Vivona N, Notarbartolo A, Averna MR. Hypertension and diabetes mellitus are associated with cardiovascular events in the elderly without cardiovascular disease. Results of a 15-year follow-up in a Mediterranean population. Nutr Metab Cardiovasc Dis. 2009 Jun;19(5):321-6. doi: 10.1016/j.numecd.2008.03.002.

18. Rigotti NA, Clair C. Managing tobacco use: the neglected cardiovascular disease risk factor. Eur Heart J. 2013 Nov;34(42):3259-67. doi: 10.1093/eurheartj/eht352.

19. Leinonen R, Heikkinen E, Jylhä M. Predictors of decline in self-assessments of health among older people - a 5 year longitudinal study. Soc Sci Med.
2001 May;52(9):1329-41. doi: 10.1016/s0277-9536(00)00249-5

20. Talarska D, Strugała M, Szewczyczak M, Tobis S, Michalak M, Wróblewska I, Wieczorowska-Tobis K. Is independence of older adults safe considering the risk of falls? BMC Geriatr. 2017 Mar; 17(1): 66. doi: 10.1186/s12877-017-0461-0.

21. Stenhagen M, Ekström H, Nordell E, Elmståhl S. Falls in the general elderly population: a 3- and 6- year prospective study of risk factors using data from the longitudinal population study 'Good ageing in Skane'. BMC Geriatr. 2013 Aug;13(81):1-11. doi: 10.1186/14712318-13-81.

22. Beauchet O, Fantino B, Allali G, Muir SW, Montero-Odasso M, Annweiler C. Timed Up and Go test and risk of falls in older adults: a systematic review. J Nutr Health Aging. 2011 Dec;15(10):933-8.

23. Martinez BP, Gomes IB, Oliveira CS, Ramos IR, Rocha MD, Forgiarini Júnior LA, Camelier FW, Camelier AA. Accuracy of the Timed Up and Go test for predicting sarcopenia in elderly hospitalized patients. Clinics (Sao Paulo). 2015 May;70(5):369-72. doi: 10.6061/ clinics/2015(05)11.

24. Visser M, Schaap LA. Consequences of sarcopenia. Clin Geriatr Med. 2011 Aug;27(3):387-99. doi: 10.1016/j.cger. 2011.03.006.

25. Beseler MR, Rubio C, Duarte E, Hervás D, Guevara MC, Giner-Pascual M, Viosca E. Clinical effectiveness of grip strength in predicting ambulation of elderly inpatients. Clin Interv Aging. 2014 Nov;9:1873-7. doi: 10.2147/CIA. S62002.

26. Cruz-Jentoft AJ, Baeyens JP, Bauer JM, Boirie Y, Cederholm T, Landi F, Martin FC, Michel JP, Rolland Y, Schneider SM, Topinková E, Vandewoude M, Zamboni M; European Working Group on Sarcopenia in Older People. Sarcopenia: European consensus on definition and diagnosis: Report of the European Working Group on Sarcopenia in Older People. Age Ageing. 2010 Jul;39(4):412-23. doi: 10.1093/ageing/afq034.

27. Gale CR, Martyn CN, Cooper C, Sayer AA. Grip strength, body composition, and mortality. Int J Epidemiol. 2007 Feb; 36(1):228-35. doi: 10.1093/ije/ dyl224

28. Simões LA, Dias JM, Marinho KC, Pinto CL, Britto RR. Relationship between functional capacity assessed by walking test and respiratory and lower limb muscle function in communitydwelling elders. Rev Bras Fisioter. 2010 Jan-Feb;14(1):24-30.

29. Carvalho J, Soares JMC. Aging and muscle strength - a brief review. Rev Port Ciên Desp. 2004;4(3):79-93.

30. Buchman AS, Boyle PA, Wilson RS, Gu L, Bienias JL, Bennett DA. Pulmonary function, muscle strength and mortality in old age. Mech Ageing Dev. 2008 Nov;129(11):625-31. doi: 10.1016/j. mad.2008.07.003. 